Ex situ formation of metal selenide quantum dots using bacterially derived selenide precursors

This article has been downloaded from IOPscience. Please scroll down to see the full text article.

2013 Nanotechnology 24145603

(http://iopscience.iop.org/0957-4484/24/14/145603)

View the table of contents for this issue, or go to the journal homepage for more

Download details:

IP Address: 130.20.178.213

The article was downloaded on 19/03/2013 at 20:45

Please note that terms and conditions apply. 


\title{
Ex situ formation of metal selenide quantum dots using bacterially derived selenide precursors
}

\author{
J W Fellowes ${ }^{1}$, R A D Pattrick ${ }^{1}$, J R Lloyd ${ }^{1}$, J M Charnock ${ }^{1}$, V S Coker ${ }^{1}$, \\ J F W Mosselmans ${ }^{2}$, T-C Weng ${ }^{3}$ and C I Pearce ${ }^{4}$ \\ ${ }^{1}$ School of Earth, Atmospheric and Environmental Sciences and Williamson Research Centre for \\ Molecular Environmental Science, Williamson Building, University of Manchester, Oxford Road, \\ Manchester, M13 9PL, UK \\ ${ }^{2}$ Diamond Light Source, Didcot, Oxfordshire, UK \\ ${ }^{3}$ SLAC National Accelerator Laboratory, Stanford, USA \\ ${ }^{4}$ Pacific Northwest National Laboratory, Richland, WA, USA \\ E-mail: Jonathan.Fellowes@manchester.ac.uk
}

Received 11 December 2012, in final form 27 February 2013

Published 18 March 2013

Online at stacks.iop.org/Nano/24/145603

\begin{abstract}
Luminescent quantum dots were synthesized using bacterially derived selenide ( $\mathrm{Se}^{\mathrm{II}-}$ ) as the precursor. Biogenic $\mathrm{Se}^{\mathrm{II}-}$ was produced by the reduction of $\mathrm{Se}^{\mathrm{IV}}$ by Veillonella atypica and compared directly against borohydride-reduced $\mathrm{Se}^{\mathrm{IV}}$ for the production of glutathione-stabilized CdSe and $\beta$-mercaptoethanol-stabilized ZnSe nanoparticles by aqueous synthesis. Biological $\mathrm{Se}^{\mathrm{II}-}$ formed smaller, narrower size distributed QDs under the same conditions. The growth kinetics of biologically sourced CdSe phases were slower. The proteins isolated from filter sterilized biogenic $\mathrm{Se}^{\mathrm{II}-}$ included a methylmalonyl-CoA decarboxylase previously characterized in the closely related Veillonella parvula. XAS analysis of the glutathione-capped CdSe at the S K-edge suggested that sulfur from the glutathione was structurally incorporated within the CdSe. A novel synchrotron based XAS technique was also developed to follow the nucleation of biological and inorganic selenide phases, and showed that biogenic $\mathrm{Se}^{\mathrm{II}-}$ is more stable and more resistant to beam-induced oxidative damage than its inorganic counterpart. The bacterial production of quantum dot precursors offers an alternative, 'green' synthesis technique that negates the requirement of expensive, toxic chemicals and suggests a possible link to the exploitation of selenium contaminated waste streams.
\end{abstract}

(Some figures may appear in colour only in the online journal)

\section{Introduction}

The use of microorganisms for the synthesis of nanocrystalline particles represents a low cost, environmentallyfriendly method of producing industrially and technologically relevant nanomaterials. Microorganisms have been used to successfully synthesize a range of nanomaterials including $\mathrm{Fe}$ oxides, precious metal catalysts and a suite of nanocrystalline, semiconducting 'quantum dots' [1-4].
The interest in quantum dots (QDs) is due to their unique semiconducting properties induced by the onset of quantum confinement in the size range 1-20 nm, generating optical, electrical and mechanical properties that differ from those of the bulk materials [5]. The photooptical and photovoltaic properties of the II/VI semiconductors (metal chalcogenides) are particularly suited for their application in solar cells and optoelectronic sensors [5-7] as well as fluorescent biolabelling, including their use in cancer screening [8-10]. 
Table 1. A number of fungal and bacterial species have been used in the synthesis of a number of metal chalcogenide nanoparticles.

\begin{tabular}{lllll}
\hline Kingdom & Microorganism & Product & Metal reactant & Reference \\
\hline Fungi & Fusarium oxysporum & $\mathrm{CdSe}$ & $\mathrm{CdCl}_{2}$ & {$[23]$} \\
& Candida glabrata & $\mathrm{CdS}$ & $\mathrm{CdSO}_{4}$ & {$[22]$} \\
& Schizosaccharomyces pombe & $\mathrm{CdS}$ & $\mathrm{CdSO}_{4}$ & {$[22,24]$} \\
& Torulopsis sp. & $\mathrm{PbS}$ & $\mathrm{Pb}\left(\mathrm{NO}_{3}\right)_{2}$ & {$[25]$} \\
& Saccharomyces cerevisiae & $\mathrm{CdTe}$ & $\mathrm{CdCl}_{2}$ & {$[26]$} \\
Bacteria & Escherichia coli & $\mathrm{CdS}$ & $\mathrm{CdCl}_{2}$ & {$[30]$} \\
& Escherichia coli & $\mathrm{CdTe}$ & $\mathrm{CdCl}_{2}$ & {$[28]$} \\
& Klebsiella pneuomoniae & $\mathrm{CdS}$ & $\left.\mathrm{Cd}^{2} \mathrm{NO}_{3}\right)_{2}$ & {$[29]$} \\
& Rhodobacter sphaeroides & $\mathrm{ZnS}$ & $\mathrm{ZnSO}_{4}$ & {$[27]$} \\
& Veillonella atypica & $\mathrm{CdSe}$ & $\mathrm{Cd}\left(\mathrm{ClO}_{4}\right)_{2}$ & {$[18]$} \\
\hline
\end{tabular}

Of all QDs synthesized, cadmium-based QDs (CdS, $\mathrm{CdSe}$ and $\mathrm{CdTe}$ ) are the most thoroughly explored owing to fluorescent emissions across the visible spectrum by direct manipulation of particle size.

Traditional organochemical synthesis of chalcogenide quantum dots involves the injection of reactants into heated organic solvents, commonly tri-n-octylphosphine oxide (TOPO). Synthesis requires the use of a number of toxic, expensive precursors and necessitates the exchange of surfactant molecules to aid aqueous solubility [11, 12]. Simpler, aqueous-based synthesis techniques have subsequently been developed in which quantum dots are produced in a reproducible, single-step reaction at temperatures $<100^{\circ} \mathrm{C}$, using surfactant molecules to increase water solubility and stability, and to limit particle growth [7, 11, 13]. Thiol compounds have been identified as ideal surfactants, and investigations by Rogach et al [14] and Gaponik et al [7] identify thioalcohols such as $\beta$-mercaptoethanol as especially suited to minimizing the size of initial precipitates. Biologically derived sulfurous materials such as the peptides glutathione (GSH) and bovine serum albumin (BSA) have also been used successfully in the aqueous synthesis of metal chalcogenide quantum dots [11, 15-21].

The whole-cell biological synthesis of II/VI quantum dots has been reported as a greener, environmentally-friendly alternative to chemical synthesis. The use of a number of fungal [22-26] and bacterial [18, 27-30] species in the formation of a range of quantum dots has been demonstrated (table 1), and exploit potential heavy metal detoxification mechanisms. $\mathrm{Cd}^{\mathrm{II}+}$ detoxification by yeast species including Schizosaccharomyces pombe, Candida glabrata $[15,16]$ and Saccharomyces cerevisiae [26] stimulates the secretion of extracellular sulfurous proteins which act as surfactants, as well as stimulating sulfide generation, resulting in extracellular deposition of peptide-coated fluorescent $\mathrm{CdS}$ nanocrystals. The use of oxyanions of the chalcogens Se and $\mathrm{Te}$ as precursors typically requires the addition of a strong reducing agent such as sodium borohydride to produce the required $\mathrm{Se}^{\mathrm{II}-}$ or $\mathrm{Te}^{\mathrm{II}-}$ anions $[1,19,21,26,28,31]$, however, Pearce et al [32] demonstrated the ability of the clinical isolate Veillonella atypica to reduce aqueous $\mathrm{Se}^{\mathrm{IV}}$ to $\mathrm{Se}^{\mathrm{II}-}$ through a biphasic reduction pathway, suggesting the possibility of linking the biosynthesis of quantum dot precursors to the bioremediation of selenium contaminated waste streams [33]. Further research on this bacterium demonstrated the feasibility of the use of biologically prepared aqueous $\mathrm{Se}^{\mathrm{II}-}$ solutions in the formation of metal selenide quantum dots [18].

This research reports on the potential for tailoring the ex situ formation of metal selenide quantum dots using bacterially generated $\mathrm{Se}^{\mathrm{II}-}$ as an alternative to chemically synthesized precursors. Biogenic and abiotic fluorescent nanoparticles were characterized and compared using UV/visible light (UV/vis) spectrophotometry, photoluminescence (PL) spectroscopy and transmission electron microscopy (TEM). Bacterial proteins present within filter sterilized biogenic $\mathrm{Se}^{\mathrm{II}-}$ solutions were identified by polyacrylamide gel electrophoresis. Potential chemical interactions between the nanoparticles and glutathione was explored using $\mathrm{S}$ K-edge synchrotron x-ray absorption spectroscopy (XAS). Finally, this work describes the effects of extracellular biological materials on the stability, nucleation and growth of $\beta$-mercaptoethanol stabilized, zinc selenide nanoparticles using a novel in situ time-resolved synchrotron XAS technique.

\section{Methods}

All chemicals used in this work were of analytical grade and acquired from Sigma-Aldrich, UK.

\subsection{Bacterial synthesis of $S e^{I I-}$}

Veillonella atypica (ATCC 14894) was grown anaerobically in defined media, coupling the reduction of $1.0 \mathrm{~g} \mathrm{l}^{-1}$ glucose to the oxidation of $7.5 \mathrm{~g} \mathrm{l}^{-1}$ sodium lactate [18]. Cells were isolated by centrifugation and re-suspended in sterile, anaerobic $20 \mathrm{mM}$ 3-( $N$-morpholino)propanesulfonic acid (MOPS) buffer at $\mathrm{pH} 7.5$ to an $\mathrm{OD}_{600}$ of $\sim 1.0$. Resting cell cultures were amended with $5 \mathrm{mM} \mathrm{Na} \mathrm{SeO}_{3}$ and $100 \mu \mathrm{M}$ of the electron shuttling compound anthraquinone2,6-disulfonate (AQDS). The head spaces of the sealed culture bottles were replaced with $\mathrm{H}_{2}$ to serve as the electron source. $\mathrm{Se}^{\mathrm{IV}}$ amended cultures were then incubated at $37^{\circ} \mathrm{C}$ for $72 \mathrm{~h}$, by which time the original colourless cell suspension had changed colour to yellow, via an intermediate red suspension.

Following incubation, the $V$. atypica $\mathrm{Se}^{\mathrm{II}-}$-containing cultures were filter sterilized under an $\mathrm{N}_{2}$ atmosphere through 
$0.22 \mu \mathrm{m}$ micropore filters. The filtered biogenic $\mathrm{Se}^{\mathrm{II}-}$ solutions were then split into $15 \mathrm{ml}$ aliquots and the $\mathrm{pH}$ was adjusted to 11.2 with $\mathrm{NaOH}$.

\subsection{Abiotic synthesis of $S e^{I I-}$}

Abiotic sodium hydrogen selenide was synthesized by adding sodium borohydride $(1.15 \mathrm{~g}, 30.5 \mathrm{mM})$ in $12.5 \mathrm{ml}$ of degassed deionized water to grey selenium powder $(1.15 \mathrm{~g}, 14.5 \mathrm{mM})$ suspended in $12.5 \mathrm{ml}$ degassed deionized water under an $\mathrm{N}_{2}$ atmosphere, at room temperature and with stirring [34]. The resulting, virtually colourless solution of NaHSe was filtered to remove crystals of $\mathrm{Na}_{2} \mathrm{~B}_{4} \mathrm{O}_{7} \cdot 10 \mathrm{H}_{2} \mathrm{O}$ that formed upon cooling of the solution after the exothermic reaction.

The NaHSe stock solution was diluted to $5 \mathrm{mM}$ with $20 \mathrm{mM}$ MOPS buffer, and the $\mathrm{pH}$ was raised to 11.2 using $\mathrm{NaOH}$ under an $\mathrm{N}_{2}$ atmosphere.

\subsection{Formation and growth of CdSe quantum dots}

A solution of $10 \mathrm{mM} \mathrm{Cd}\left(\mathrm{ClO}_{4}\right)_{2}$ and $30 \mathrm{mM}$ reduced glutathione $(\mathrm{GSH})$ was prepared so that the final molar ratio upon mixing would be 2:1:3 (Cd:Se:GSH). High purity $\mathrm{N}_{2}$ was bubbled through the $\mathrm{Cd}^{\mathrm{II}+}-\mathrm{GSH}$ solution to remove $\mathrm{O}_{2}$. The $\mathrm{pH}$ was then adjusted using $\mathrm{NaOH}$ under an $\mathrm{N}_{2}$ atmosphere to 11.2. Solutions of abiotic and biogenic $\mathrm{Se}^{\mathrm{II}-}$ and $\mathrm{Cd}^{\mathrm{II}+}{ }_{-} \mathrm{GSH}$ were chilled in an ice bath for $1 \mathrm{~h}$. Aliquots of the $\mathrm{Se}^{\mathrm{II}-}$ solutions were injected rapidly into equal volumes of the $\mathrm{Cd}^{\mathrm{II}+}$-GSH solutions under an oxygen-free atmosphere, and were shaken vigorously for $30 \mathrm{~s}$ until a yellow precipitate was observed. The GSH-CdSe suspension was then transferred in to a three-necked round bottom glass and refluxed on a heating mantle at $100^{\circ} \mathrm{C}$. Aliquots were taken at 4 min time intervals until no suspension remained. Aliquots were immediately quenched in liquid nitrogen and stored at $-80^{\circ} \mathrm{C}$ prior to analysis.

\subsection{Characterization of CdSe quantum dots}

The UV/vis absorption spectra of the reaction suspension aliquots were measured with an Analytik Jena Specord S600 (Analytik Jena AG, Germany). Photoluminescence spectra were taken with a Gilden Photonics Fluorosens (Guilden Photonics Ltd, UK), using a constant excitation wavelength of $365 \mathrm{~nm}$.

HR-TEM images were taken using an FEI Tecnai F20 FEGTEM $(200 \mathrm{kV})$, fitted with an Oxford Instruments $80 \mathrm{~mm}^{2}$ XMAX SDD EDX detector and a Gatan Orius SC200 CCD. TEM samples were prepared by dropping an aliquot of QDs in water onto a 400-mesh carbon-coated copper grid (Agar Scientific, UK). Particle sizing was via analysis of TEM images, with more than 100 particles assessed at each sample time point for statistical accuracy.

\subsection{Protein identification}

To analyse for protein in the selenide solutions, $25 \mu$ l fractions of the abiotic and biogenic $\mathrm{Se}^{\mathrm{II}-}$ solutions were run in an $18 \%$ Tris-HCl gel with Tris/glycine/SDS running buffer. Kaleidoscope (BioRad) prestained molecular weight ladders were run on both sides of the gel and gel-separated protein bands were detected using Imperial Protein Stain. Bands of interest were excised under sterile conditions for trypsin digestion. Tryptic peptides were analysed using liquid chromatography-based high-resolution tandem mass spectrometry (LC-MS/MS), comprising an Ultimate 3000 (LC-Packings, Dionex, Amsterdam, The Netherlands) coupled to a HCT Ultra ion trap mass spectrometer (Bruker Daltonics, Bremen, Germany). All samples were searched first against the SWISSPROT database searching all species, and then against either a species-specific search in UNIPROT, or against a species-specific database.

\subsection{XAS analyses}

XAS analyses of the S K-edge were undertaken at the Diamond Light Source, Oxfordshire, UK on the microfocus spectroscopy beamline I18 with the aim of examining the structural relationship between the sulfur component of the glutathione capping agent and the CdSe nanocrystals. Measurements were taken with an unfocused beam in fluorescence mode with a 4 element $\mathrm{Si}$ drifts detector. A range of standards were measured, including oxidized and reduced forms of glutathione, elemental sulfur, sodium sulfite and sodium sulfate. To remove any MOPS buffer, AQDS and unreacted glutathione, GSH-CdSe was concentrated and purified by re-suspension in the nonsolvent 2-propanol as previously described [7, 18].

Further XAS experiments at the Se K-edge (about $12654 \mathrm{eV}$ ) were carried out on the high brilliance $\mathrm{x}$-ray spectroscopy beamline ID26 at the European Synchrotron Radiation Facility (ESRF), Grenoble, France, using a $\langle 111\rangle$ double $\mathrm{Si}$ crystal monochromator as described previously [35]. The aim was to examine the differences between the formation of chalcogenide QDs from abiotic and biogenic selenide precursors. In this case, the development of $\mathrm{ZnSe}$ with the use of $\beta$-mercaptoethanol ( $\beta \mathrm{ME}$ ) as a capping agent ( $\beta \mathrm{ME}-\mathrm{ZnSe})$ was used as an analogue system to CdSe. Owing to the speed of the reaction, which exceeds that which can be seen by QUEXAFS, a novel, in situ, time-resolved experiment was carried out using an injection cell system. The $\beta \mathrm{ME}-\mathrm{ZnSe}$ was synthesized by injecting equal volumes of an anaerobic solution containing $10 \mathrm{mM} \mathrm{ZnCl}_{2}$ and $24 \mathrm{mM}$ $\beta \mathrm{ME}$ solution and an anaerobic solution of the appropriate $\mathrm{Se}^{\mathrm{II}-}(5 \mathrm{mM})$ to produce final concentrations of $\mathrm{Zn}$, Se and $\beta \mathrm{ME}$ of $5,2.5$ and $12 \mathrm{mM}$ respectively. Initial XAS scans were taken across the Se K-edge after the injection of equal volumes of degassed, deionized water and the abiotic or biogenic $\mathrm{Se}^{\mathrm{II}-}$ solutions, and also after the injection of the $\mathrm{Zn}^{\mathrm{II}+}-\beta \mathrm{ME}$ and the abiotic or biogenic $\mathrm{Se}^{\mathrm{II}-}$ solutions. From these, it was possible to discern two regions of significant difference between the $\mathrm{Se}^{\mathrm{II}-}$ and $\mathrm{ZnSe}$ phases that allowed the reaction and development of $\mathrm{ZnSe}$ products to be monitored. The sample cell was then flushed with anaerobic, deionized $\mathrm{H}_{2} \mathrm{O}$ before re-use. The multi element $\mathrm{Ge}$ detector was set to analyse at the specified energy with the minimum refresh rate of $0.5 \mathrm{~ms}$ during the injection of $\mathrm{Zn}^{\mathrm{II}+}-\beta \mathrm{ME}$ and $\mathrm{Se}^{\mathrm{II}-}$. The sample cell was then flushed and repeated for both stated energies for the abiotic and biogenic $\mathrm{Se}^{\mathrm{II}-}$ solutions. 


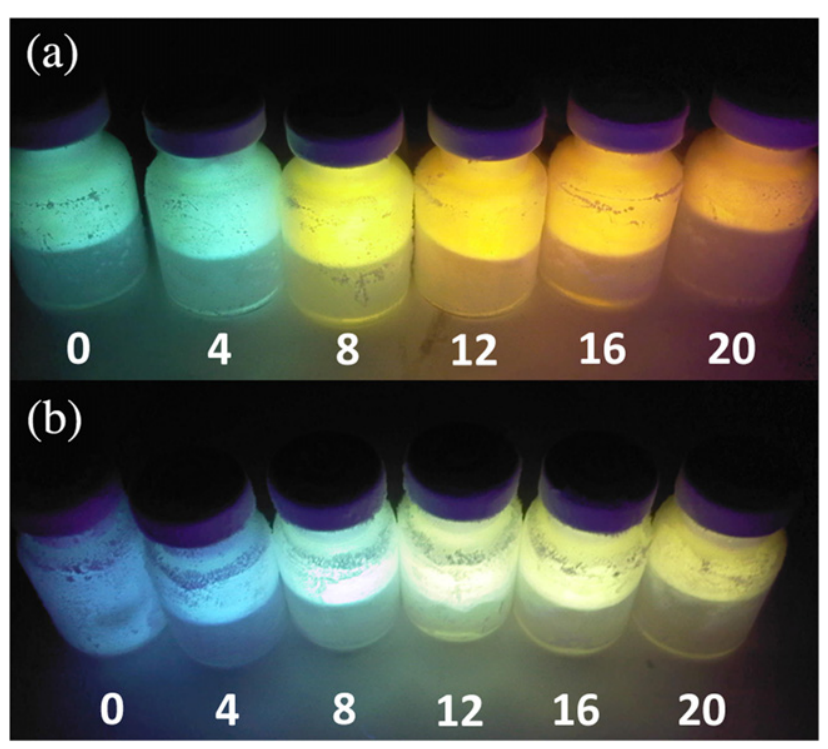

Figure 1. (a) Abiotic and (b) biogenic GSH-CdSe quantum dots fluorescing under $365 \mathrm{~nm}$ UV irradiation at different reflux time points.

\section{Results and discussion}

\subsection{Particle characterization and development}

The production of glutathione-stabilized cadmium selenide quantum dots by abiotic and biogenic routes was compared. In both cases, the GSH-CdSe suspensions changed colour from yellow to red during refluxing, corresponding to the growth of quantum dots. The fluorescence under UV illumination at a wavelength of $365 \mathrm{~nm}$ is shown in figure 1. The UV/vis absorption spectra of these GSH-CdSe aliquots are shown in figure 2. Both abiotic- and biogenic-derived sample sets display primary and secondary absorption peaks for the 0 and 4 min reflux time points; at 356 and $408 \mathrm{~nm}$ for the abiotic samples, and at 314 and $334 \mathrm{~nm}$ for the biogenic samples. The relative intensity of the secondary, lower wavelength absorption peaks decreased with increasing reflux time for both abiotic and biogenic samples. The peak absorption wavelength for both sets of samples increased with increasing reflux time (figure 2), and a second absorption peak was observed in the abiotic sample sets approximately $30 \mathrm{~nm}$ above the primary absorption peak.

To quantify the photoluminescence observed in figure 1 , the GSH-CdSe quantum dots were analysed using a constant excitation wavelength of $365 \mathrm{~nm}$ and the results are shown in figure 2. The peak emission wavelength for the abiotic GSH-CdSe prior to reflux was at $510 \mathrm{~nm}$, which increased to $590 \mathrm{~nm}$ following $20 \mathrm{~min}$ of refluxing. The biogenic QDs prior to reflux also had a peak emission wavelength of $510 \mathrm{~nm}$, which increased to $531 \mathrm{~nm}$ following refluxing for the same period, $59 \mathrm{~nm}$ lower than that of the abiotic QDs. A large shift in emission spectra was observed for the abiotic QDs between 4 and 12 min refluxing time, which was not observed in the biogenic photoluminescence spectra. Secondary emission peaks occurred in the abiotic GSH-CdSe photoluminescence spectra at $117 \mathrm{~nm}$ above the peak emission wavelength (figure 2), becoming more prominent with prolonged reflux time. The biogenic spectra initially showed a secondary emission peak occurring $13 \mathrm{~nm}$ above the primary emission wavelength (figure 2), but this peak disappeared with subsequent refluxing.
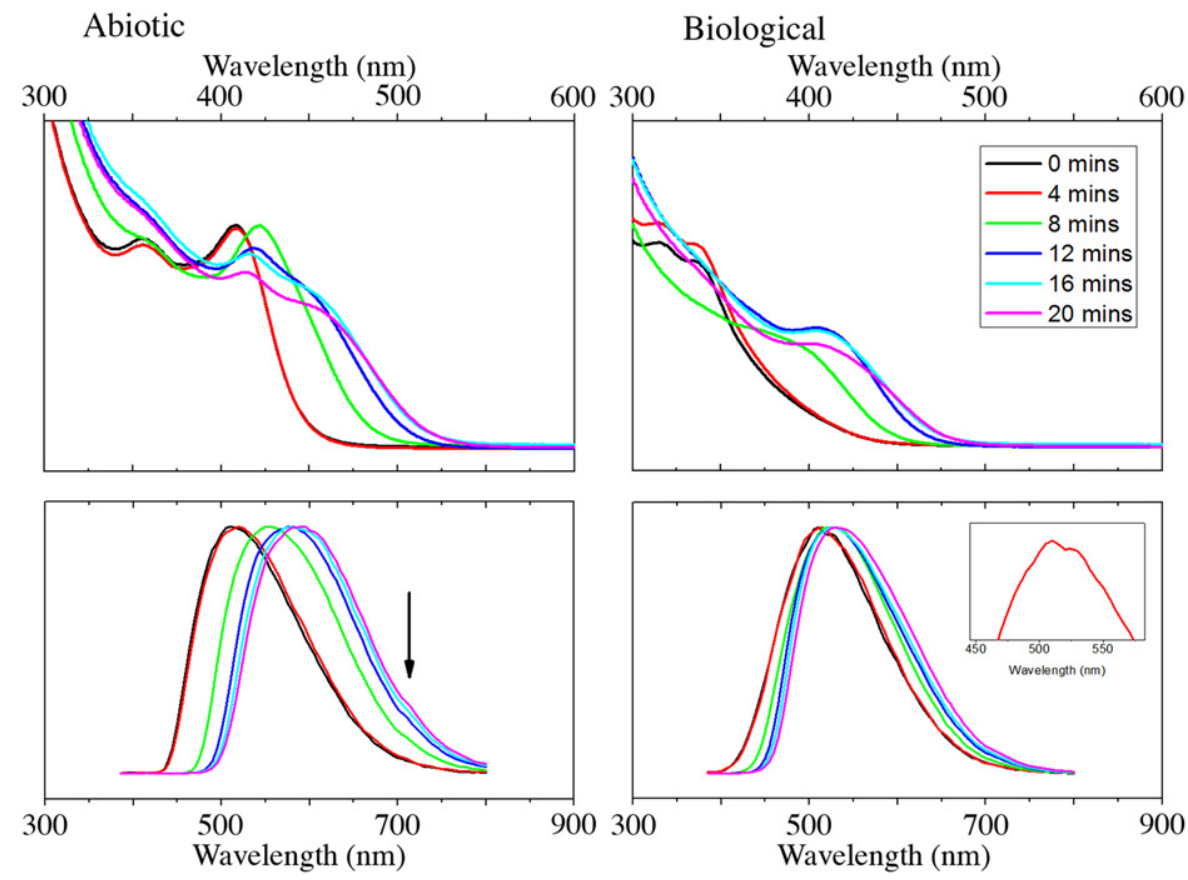

Figure 2. UV/vis (top) and photoluminescence (bottom) spectra for GSH-CdSe QDs synthesized from abiotic Se ${ }^{\mathrm{II}-}$ (left) and biogenic $\mathrm{Se}^{\mathrm{II}-}$ (right). Arrow (bottom left) and inset (bottom right) highlight secondary peaks. 


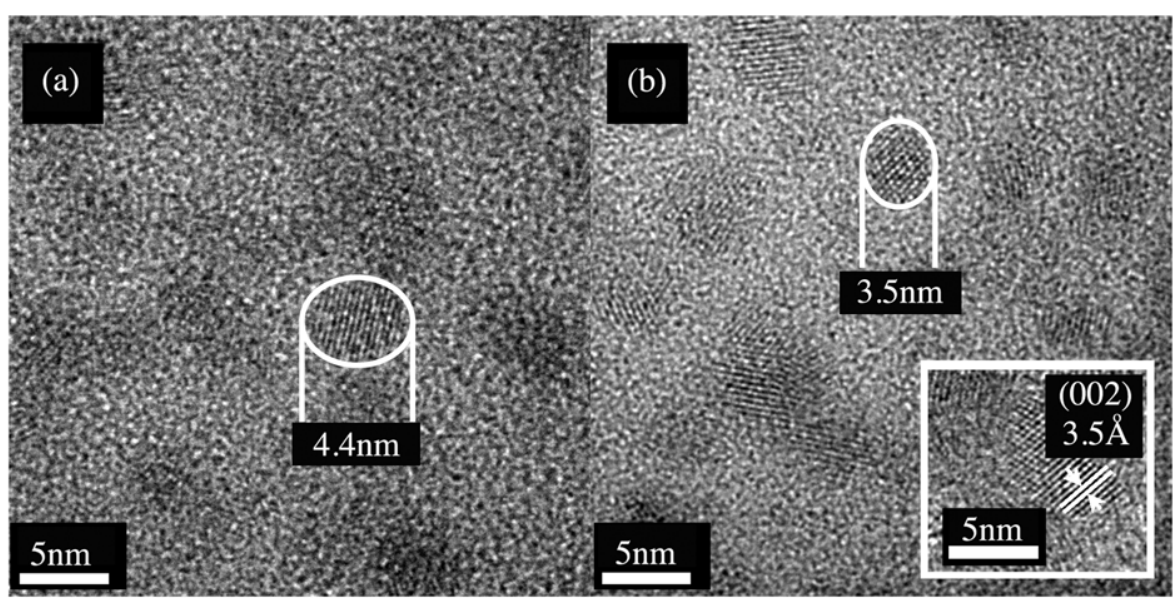

Figure 3. HR-TEM imaging showing (a) abiotic and (b) biogenic GSH-CdSe, showing QDs synthesized after 8 min refluxing at $100{ }^{\circ} \mathrm{C}$. Individual crystals are highlighted. (inset) The crystal lattice is visible, and the lattice spacing of $3.5 \AA$ corresponds to the (002) plane of hexagonal cadmoselite.
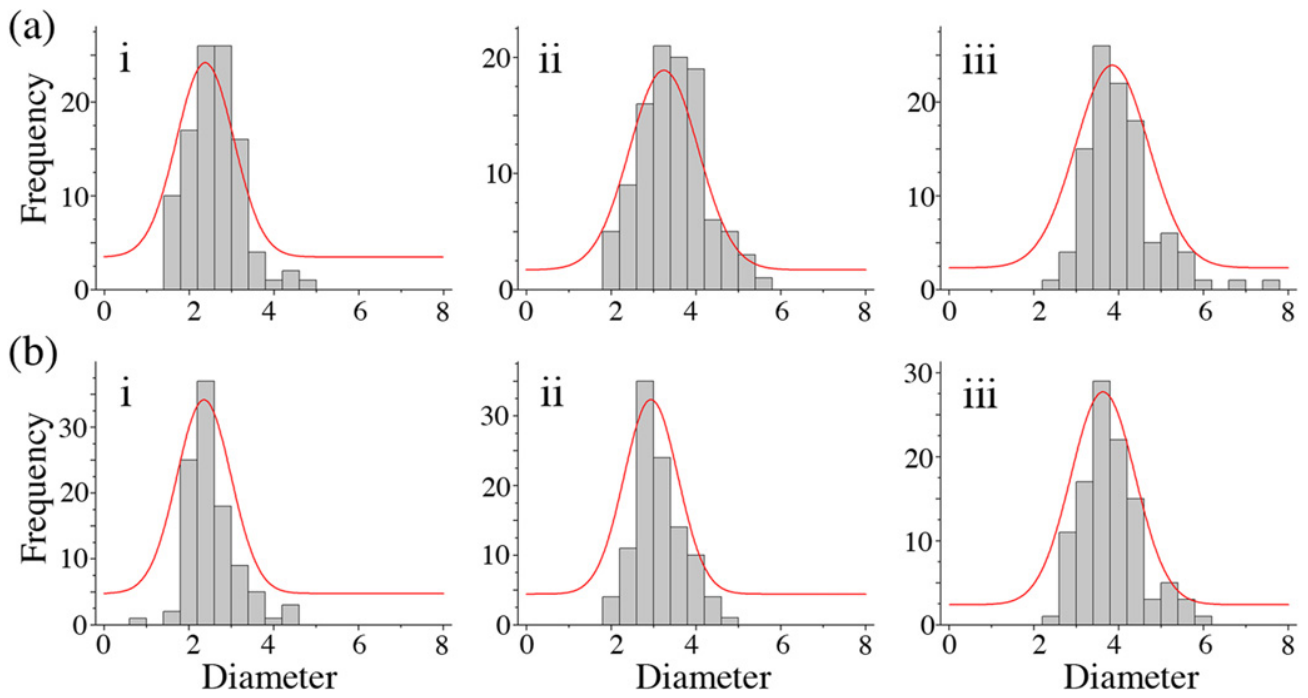

Figure 4. Particle size distributions as determined by HR-TEM. (A) Abiotic GSH-CdSe particles at (i) 0 min, (ii) 8 min and (iii) $20 \mathrm{~min}$ reflux time. (B) Biogenic GSH-CdSe particles at (i) $0 \mathrm{~min}$, (ii) $8 \mathrm{~min}$ and (iii) $20 \mathrm{~min}$ reflux time. Gaussian distributions for the average particle size are overlaid. For statistical analysis, over 100 particles were used from each time point.

HR-TEM was employed to characterize the particle size shape and morphology of the QD reflux aliquots (figure 3). Spherical, crystalline CdSe particles with diameters of less than $8 \mathrm{~nm}$ were discernable, and lattice fringe measurements corresponded to d-space values of planes within hexagonal CdSe (cadmoselite, ICDD 00-008-0459).

Particle size distributions were calculated using HR-TEM images, and the resulting histograms are shown in figure 4. Abiotic and biogenic QDs initially showed equal average particle diameters of $2.3 \mathrm{~nm}( \pm 1.3 \mathrm{~nm}$ for both biogenic and abiotic). An increase in size distribution was noted, however, for the abiotic QDs after 8 min reflux, with an average particle diameter of $3.2 \mathrm{~nm} \pm 1.2 \mathrm{~nm}$ compared to $2.9 \mathrm{~nm} \pm 1.2 \mathrm{~nm}$ for the biogenic QDs. Following 20 min reflux, average particle diameters increased to $3.8 \mathrm{~nm} \pm 1.2 \mathrm{~nm}$ and $3.6 \mathrm{~nm} \pm 1.2 \mathrm{~nm}$ for abiotic and biological QDs, respectively.
Figure 5 shows the peak photoemission wavelength, the first order derivative of the peak photoemission wavelength and the average particle diameter determined by TEM. Using the peak photoemission wavelength as a proxy for particle size, the derivative of this can infer the rate of change of particle growth rate as a factor of temperature at 4 min intervals between sampling. These results show that the rate of change in the peak photoemission wavelength (and accordingly the particle size) increases dramatically above $90^{\circ} \mathrm{C}$ for the abiotically synthesized QDs, whereas the biogenic QDs display a lower, stable growth rate in this temperature range. PL spectra (figure 2) and particle size distributions from HR-TEM (figure 4) for both abiotic and biogenic QDs show a non-Gaussian size distribution with a tail extending to the high particle sizes.

The results of these analyses show that biogenic $\mathrm{Se}^{\mathrm{II}-}$ is a viable alternative to abiotically generated $\mathrm{Se}^{\mathrm{II}-}$ in the 


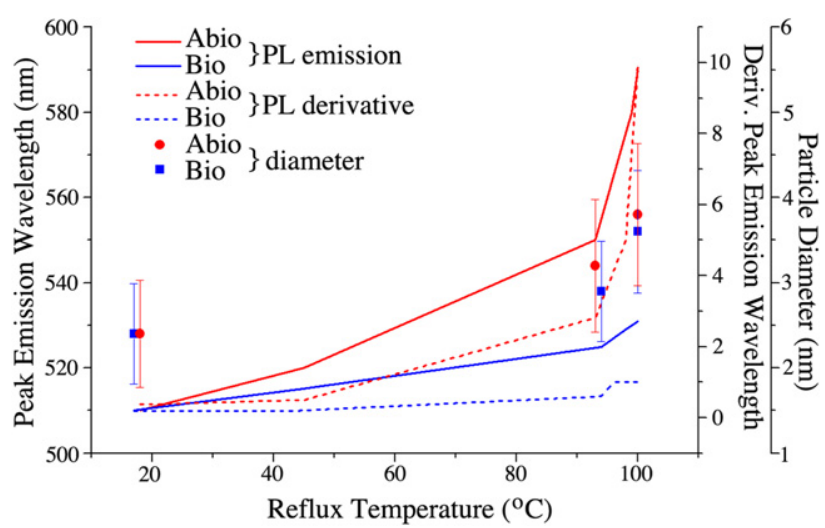

Figure 5. Peak photoluminescence emission wavelength (solid lines), the first order derivative of the peak photoluminescence emission wavelength (dashed lines), and the average particle diameter as determined by TEM for the abiotically synthesized QDs (red circles) and the biogenically synthesized QDs (blue squares).

formation of metal selenide quantum dots, alleviating the need for highly toxic and strongly reducing compounds. Analysis of the optical absorption and emission spectra (figure 2) shows that biogenic $\mathrm{Se}^{\mathrm{II}-}$ can be used as a precursor for the synthesis of highly fluorescent nanoparticles comparable to abiotic equivalents. Particle sizing in conjunction with UV/vis and PL emission spectra show that the growth of biogenic QDs occurs at a slower rate than with abiotically generated $\mathrm{Se}^{\mathrm{II}-}$, suggesting that the presence of bacterially derived moieties, such as proteins, may inhibit the growth rate of CdSe QDs.

The more consistent particle size of the biotic samples could be attributable to a particle size control dictated by coordinating bacterially derived moieties, such as previously reported for sulfurous peptides $[11,15-17,19,21]$. The development of the large particle size fraction is a deleterious characteristic of aqueous QD synthesis techniques in comparison with organometallic synthesis routes, and although the presence of bacterial proteins leads to an increased control of particle growth by reducing particle growth rate (figure 5), a post-preparative purification step as used by Gaponik et al [7] may be required.

\subsection{Protein identification}

The impact of secreted bacterial and fungal proteins on the nucleation and growth of metal chalcogenide quantum dots has been observed previously [15, 16, 19, 22, 26, 28]. In order to determine the nature of the bacterially derived moieties in the biogenic $\mathrm{Se}^{\mathrm{II}-}$ solution in this study, both the biogenic and the abiotic $\mathrm{Se}^{\mathrm{II}-}$ solutions were analysed for protein content by SDS-PAGE (figure 6).

No protein bands were visible in the abiotic $\mathrm{Se}^{\mathrm{II}-}$ solution; however the red-orange band at the end of the gel for both the biogenic and abiotic samples indicates the precipitation of elemental selenium nanoparticles as a result of oxidation of the selenide solution. The biogenic $\mathrm{Se}^{\mathrm{II}-}$ solution contained a range of proteins of varying mass, of which one was putatively identified as the alpha-subunit of methylmalonyl-CoA decarboxylase, similar to that identified

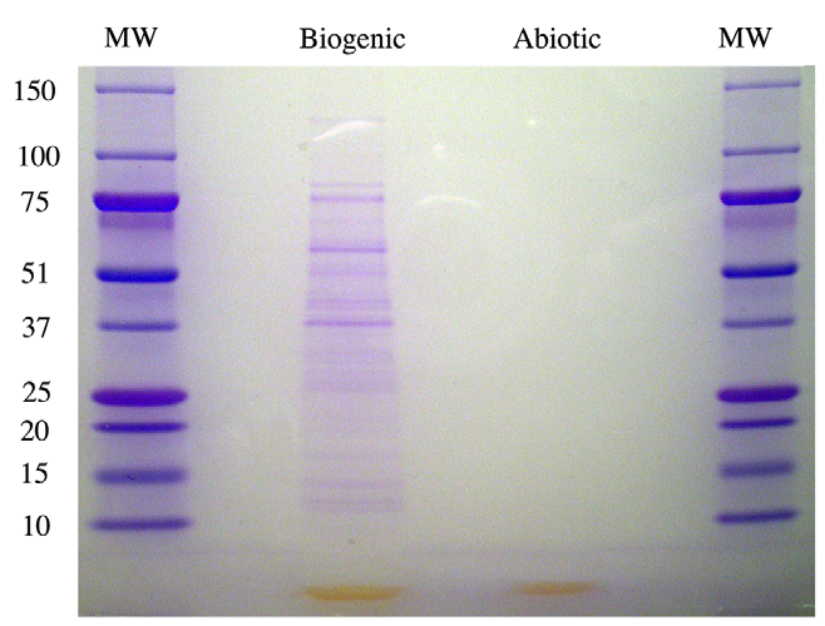

Figure 6. SDS-PAGE of biogenic $\mathrm{Se}^{\mathrm{II}-}$ produced by $V$. atypica and abiotic $\mathrm{Se}^{\mathrm{II}-}$. Molecular weight standards are to the right and left. Red staining at the bottom of the gel is due to the precipitation of elemental selenium particles.

in Veillonella parvula [36], and likely originating from $V$. atypica.

\subsection{XAS investigations}

\subsubsection{Bonding of the reduced glutathione capping agent.}

The coordination environment of sulfur in the reduced glutathione capping agent associated with the CdSe quantum dots was investigated using XAS at the S K-edge; the XANES results are shown in figure 7 , along with relevant model compounds. The XANES spectra of the model compounds show a range of spectral shapes and peak energies with an approximately $10 \mathrm{eV}$ difference in peak energy between elemental $\mathrm{S}$ and $\mathrm{S}$.

The spectral profile and absorption edge energy at the S K-edge obtained for the precipitated GSH-CdSe QDs show that $\mathrm{S}$ is present in a reduced form, and closely resembles the CdS standard at about $2473 \mathrm{eV}$ (figure 7). There is no evidence for the presence of $\mathrm{S}-\mathrm{S}$ bonds as in oxidized GSH, or S-O bonds as the oxidized sulfate or sulfite forms. There are two possible $\mathrm{Cd}-\mathrm{S}$ coordination environments within the samples tested; (i) the Cd-SR bond, where $\mathrm{R}$ is the glutathione molecule, between $\mathrm{Cd}$ atoms exposed at the surface of the nanoparticles and the $\mathrm{S}$ of the cysteine component within glutathione, in which the $\mathrm{Cd}-\mathrm{S}$ bonds show similar character to those observed for xanthate attachment to $\mathrm{ZnSe}$ [37]; and (ii) structural incorporation of free $S$ into a mixed $\mathrm{CdSe}_{1-x} \mathrm{~S}_{x}$ phase, due to the decomposition of glutathione during reflux in alkaline, aqueous media, as reported for the incorporation of $\mathrm{S}$ into CdTe quantum dots [7, 38]. Gaponik et al [7] postulated that excess thiol, coupled with decreasing free $\mathrm{Se}^{2-}$ concentrations as particles grow during reflux, increases the proportion of S structurally incorporated, thereby causing an increasing S:Se ratio in the outer layers of the particle. However, the limitation of the QD particle size to below $4 \mathrm{~nm}$ is evidence that the Cd-SR bond is restricting particle growth. Differentiating between sulfur attached to 


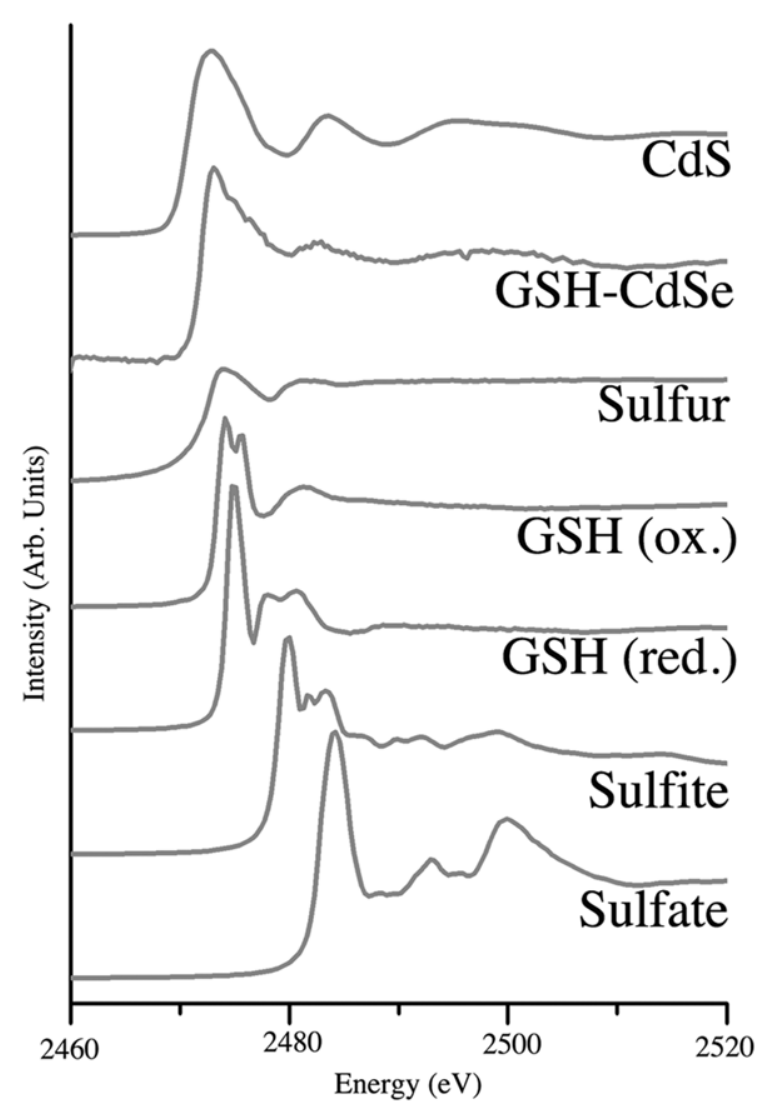

Figure 7. S K-edge XANES spectra showing model compounds compared to the experimental GSH-CdSe sample. From the bottom: sodium sulfate, sodium sulfite, reduced and oxidized glutathione, elemental sulfur, the experimentally derived biogenic GSH-CdSe, and CdS.

cadmium at the surface and sulfur structurally incorporated into the outer CdSe layers is not possible using standard XANES techniques. Understanding the relationship between sulfurous capping agents and metal selenide QDs, as well as determining the relative proportions of the $\mathrm{Cd}-\mathrm{SR}$ and the $\mathrm{CdSe}_{1-x} \mathrm{~S}_{x}$ during particle growth, is challenging and requires collection of an extended $\mathrm{x}$-ray absorption fine structure (EXAFS) time course data set, at the S K-edge, covering QD formation and growth during reflux. This will be the focus of future research.

3.3.2. Selenide stability and ZnSe nucleation. XAS was used to compare the stability of biogenic and abiotic $\mathrm{Se}^{\mathrm{II}-}$ starting materials, in order to determine the impact of extracellular biological materials (figure 8). As with $\mathrm{S}$, an increase in oxidation state of Se at the K-edge is easily discernable by an increase in absorption edge energy $\left(7.5 \mathrm{eV}\right.$ between $\mathrm{Se}^{0}$ and $\mathrm{Se}^{\mathrm{VI}}$ ).

The results show that the initial biogenic $\mathrm{Se}^{\mathrm{II}-}$ solution was composed predominantly of $\mathrm{Se}^{\mathrm{II}-}$ with a peak at $12653.5 \mathrm{eV}$, but with the possible presence of a minor oxidized component as indicated by the broad bimodal lineshape (figure 8). The stability of the abiotic and biogenic $\mathrm{Se}^{\mathrm{II}-}$ solutions was compared by repeated scanning across the Se K-edge for $15 \mathrm{~min}$ (figure 8). Over this time period, the

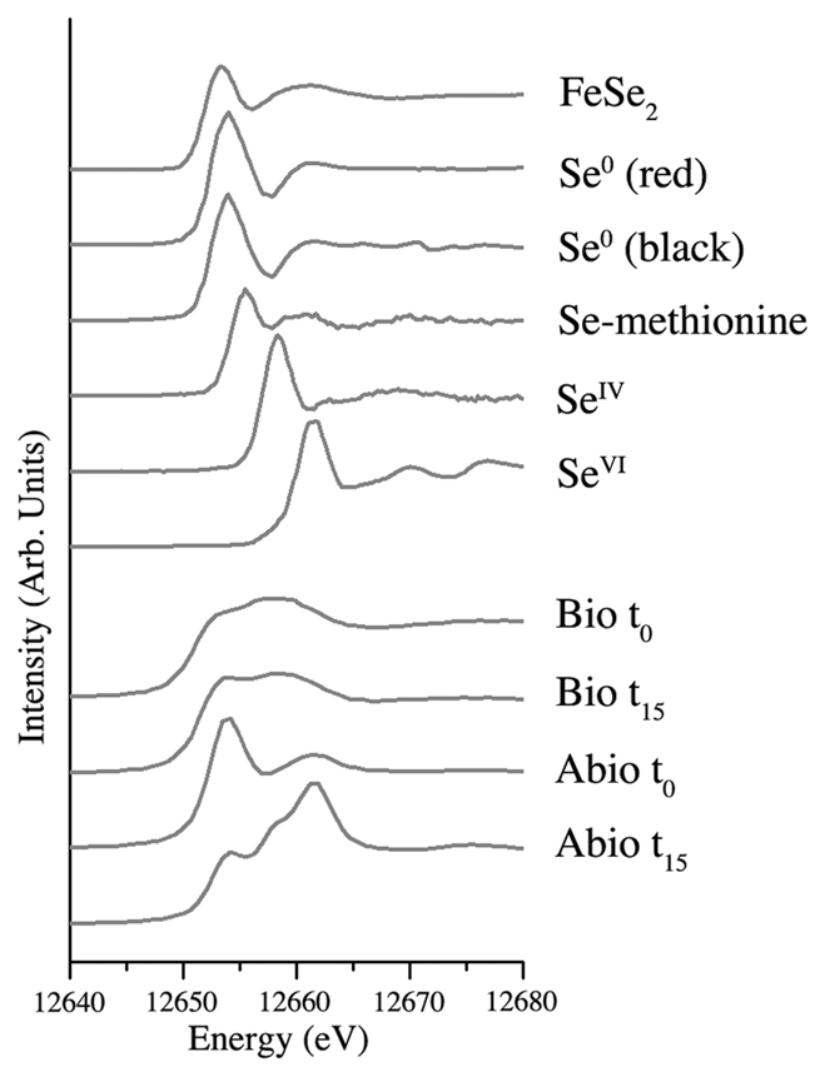

Figure 8. Se K-edge XANES spectra for model compounds (top) iron selenide, red elemental selenium, black elemental selenium, selenomethionine, sodium selenite, sodium selenate and experimental products (bottom) investigating the stability of the biogenic and abiotic $\mathrm{Se}^{\mathrm{II}-}$ solutions before and after exposure to the synchrotron $\mathrm{x}$-ray beam for $15 \mathrm{~min}$.

biogenic $\mathrm{Se}^{\mathrm{II}-}$ solution remained in a reduced form indicating that it was stable and did not undergo oxidation. However, the abiotic $\mathrm{Se}^{\mathrm{II}-}$ peak shifted dramatically towards a principally $\mathrm{Se}^{\mathrm{VI}}$ form, after $15 \mathrm{~min}$ exposure to the beam, indicating that the abiotic $\mathrm{Se}^{\mathrm{II}-}$ was susceptible to oxidation, possibly induced by the $\mathrm{x}$-rays. The proteins identified in the biogenic $\mathrm{Se}^{\mathrm{II}-}$ solution may coordinate with the $\mathrm{Se}^{\mathrm{II}-}$ and act as stabilizing agents, limiting oxidation.

The addition of the $\mathrm{ZnCl}_{2}-\beta \mathrm{ME}$ solution to both biogenic and abiotic $\mathrm{Se}^{\mathrm{II}-}$ stocks leads to the rapid formation of $\beta \mathrm{ME}-\mathrm{ZnSe}$ nanocrystals, as shown in figure 9. From these spectra, there is a discernable difference in absorption intensity at 12661 and $12667 \mathrm{eV}$ between the $\mathrm{Se}^{\mathrm{II}-}$ solutions and $\beta \mathrm{ME}-\mathrm{ZnSe}$ suspensions for both the biogenic and abiotic samples. The change in intensity at these energies defines the rate of nucleation of $\mathrm{ZnSe}$ QDs, both in the presence and absence of extracellular biological material (figure 10). First order derivatives of the time-resolved spectra obtained highlight differences in the rate of transformation from the $\mathrm{Se}^{\mathrm{II}-}$ phase to the $\mathrm{ZnSe}$ phase, with the biogenic $\mathrm{Se}^{\mathrm{II}-}$ samples displaying a wider peak than abiotic counterparts; full-width half-maximum (FWHM) values for these reactions are $1.25 \mathrm{~ms}$ and $1.23 \mathrm{~ms}$ for the biogenic $\mathrm{Se}^{\mathrm{II}-}$ samples at $12661 \mathrm{eV}$ and $12667 \mathrm{eV}$, respectively and $0.77 \mathrm{~ms}$ and 


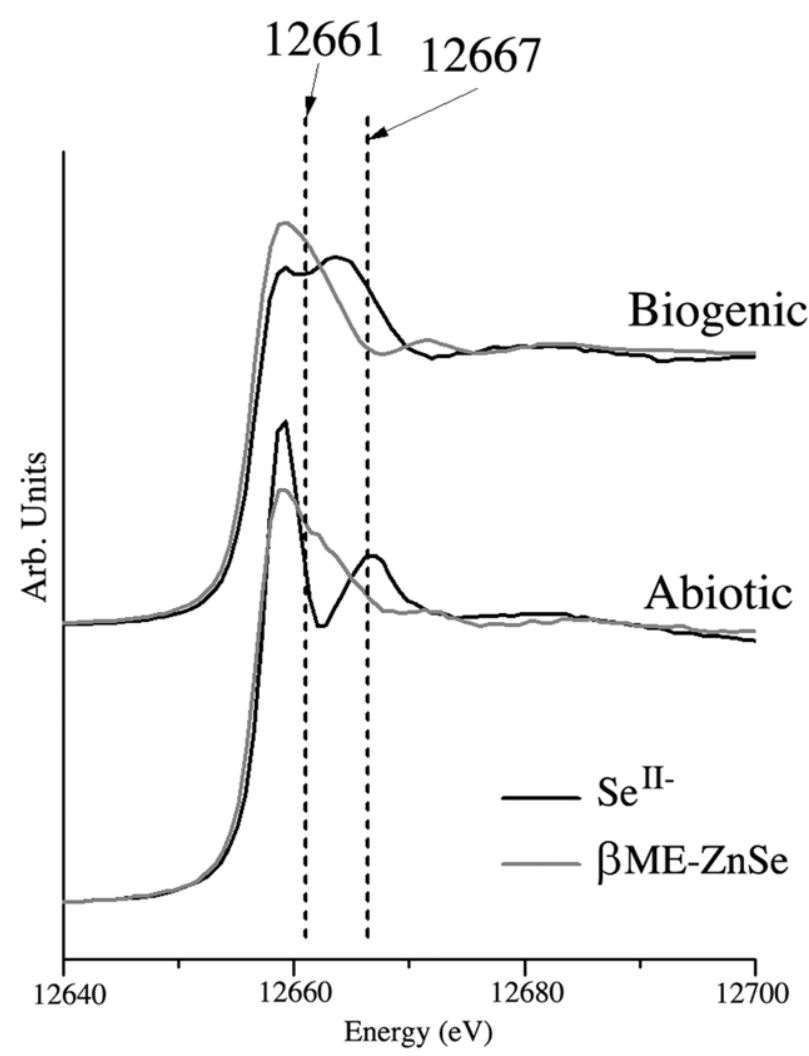

Figure 9. Se K-edge x-ray absorption spectra for the biogenic (top) and abiotic (bottom) $\mathrm{Se}^{\mathrm{II}-}$ solutions (black lines) and $\beta$-mercaptoethanol capped $\mathrm{ZnSe}$ (grey lines) formed following addition of $\mathrm{ZnCl}_{2}$. The energies used for the time-resolved scans are indicated.
$0.74 \mathrm{~ms}$ for the abiotic $\mathrm{Se}^{\mathrm{II}-}$ samples at $12661 \mathrm{eV}$ and $12667 \mathrm{eV}$.

It is possible that proteins present in the biogenic $\mathrm{Se}^{\mathrm{II}-}$ are also implicated in decreasing the rate of reaction between $\mathrm{Zn}^{\mathrm{II}+}$ and $\mathrm{Se}^{\mathrm{II}-}$, as shown in figure 10 where the FWHM value for two independent biogenic $\mathrm{Se}^{\mathrm{II}-}$ reactions are twice that for those obtained with abiotic $\mathrm{Se}^{\mathrm{II}-}$. However, there are limitations associated with these results, as the FWHM reaction times calculated are of the same magnitude as the minimum detector refresh rate $(0.5 \mathrm{~ms})$, although the repetition of the results from two separate biogenic $\mathrm{Se}^{\mathrm{II}-}$ reactions and two abiotic $\mathrm{Se}^{\mathrm{II}-}$ reactions suggests these findings are valid; further investigations using ultrafast time-resolved detectors is warranted.

\section{Conclusions}

The technological, industrial and biological advances using semiconducting, nanoparticulate 'quantum dots' merits the investigation of techniques aimed at reducing the economic and environmental costs associated with their manufacture. In this study, we have compared the formation of metal selenide quantum dots from bacterially derived $\mathrm{Se}^{\mathrm{II}-}$ with quantum dots synthesized from tradition chemical precursors. The use of bacterially derived $\mathrm{Se}^{\mathrm{II}-}$ in the manufacture of metal selenide quantum dots controls the rate of formation and growth of the QDs, with a decrease in initial reaction rate and a narrower size distribution of particles in comparison to abiotic counterparts, even in the presence of thiol capping agents. The decreased particle size distribution and the
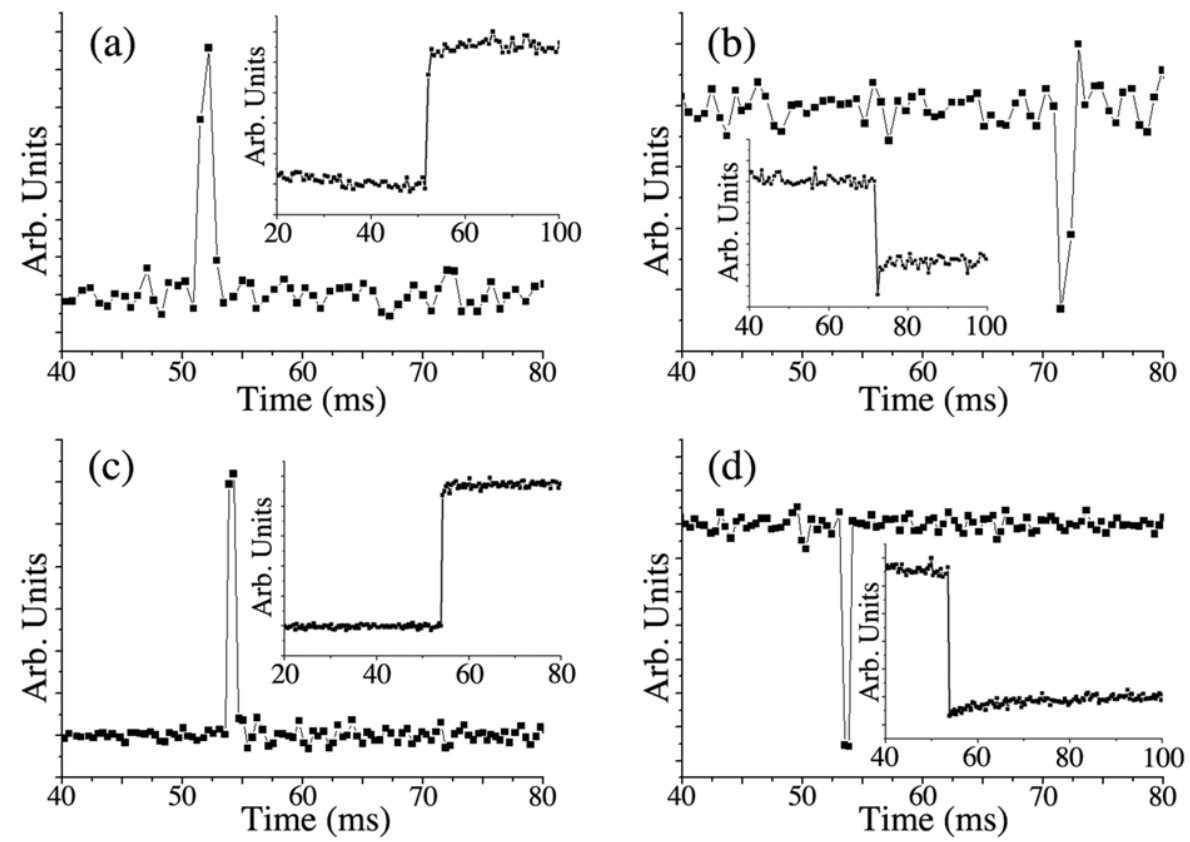

Figure 10. Time-resolved energy scans (main image: first order derivates, inset: time-resolved scans) for (A) biogenic ZnSe at 12661 eV, (B) biogenic $\mathrm{ZnSe}$ at $12667 \mathrm{eV},(\mathrm{C})$ abiotic $\mathrm{ZnSe}$ at $12661 \mathrm{eV}$ and (D) abiotic ZnSe at $12667 \mathrm{eV}$. Inset: $X$ axis values are time in milliseconds. 
reduced particle growth rate allow for tighter size constraints with biotic materials compared to wet synthesis experiments with abiotic $\mathrm{Se}^{\mathrm{II}-}$.

Protein gel electrophoresis has shown that bacterial contributions to the synthesis of technologically relevant materials is not limited to direct formation of the $\mathrm{Se}^{\mathrm{II}-}$ solutions; extracellular biological materials play an important role in $\mathrm{Se}^{\mathrm{II}-}$ stability after the cells have been removed. S K-edge XANES has supported the hypothesis that GSH acts as a capping agent and is attached to the surface of the QDs. Novel, in situ time-resolved XAS experiments have also demonstrated that the presence of bacterially derived proteins provides increased control over QD size by reducing the rate of initial particle formation.

This research describes an alternative, 'green' pathway that utilizes the advantages of biosynthetic techniques, namely the cheap, low temperature and relatively safe synthesis of $\mathrm{Se}^{\mathrm{II}-}$ without the use of highly toxic and expensive precursors. The results also highlight the stability of the precursors and enhanced control of QD synthesis that can be obtained in the presence of biological coatings. Further research into the characterization and optimization of the role of bacterially derived sulfurous capping agents in metal selenide quantum dot formation is warranted prior to assessing the economic viability and scalability of this technique on an industrial scale.

\section{Acknowledgments}

The authors wish to acknowledge the assistance of the following; Dr Mike Ward for TEM under the LENNF scheme (University of Leeds and EPSRC Grant EP/F056311/1); the research group of Professor Paul O'Brien, School of Chemistry, University of Manchester; Dr David Knight and Ms Emma-Jane Keevill of the Biomolecular Analysis Facility, University of Manchester. This work was carried out with the support of the Diamond Light Source, utilizing the I18 Microfocus Spectroscopy beamline. We acknowledge the European Synchrotron Radiation Facility for provision of synchrotron radiation facilities and we would like to thank Dr P Glatzel for assistance in using the ID26-X-ray absorption and emission spectroscopy beamline. Finally, the authors wish to acknowledge the financial assistance of NERC, UK.

\section{References}

[1] Crookes-Goodson W J, Slocik J M and Naik R R 2008 Bio-directed synthesis and assembly of nanomaterials Chem. Soc. Rev. 37 2403-12

[2] Lloyd J R et al 2008 Biomineralization: linking the fossil record to the production of high value functional materials Geobiology 6 285-97

[3] Macaskie L E et al 2010 Today's wastes, tomorrow's materials for environmental protection Hydrometallurgy 104 483-7

[4] Lloyd J R, Byrne J M and Coker V S 2011 Biotechnological synthesis of functional nanomaterials Curr. Opin. Biotechnol. 22 509-15

[5] Trindade T, O'Brien P and Pickett N L 2001 Nanocrystalline semiconductors: synthesis, properties, and perspectives Chem. Mater. 13 3843-58
[6] Berg T W and Hvam J M 2004 Optics of Semiconductors and their Nanostructures ed H Kalt and M Hetterich (Berlin: Springer)

[7] Gaponik N, Talapin D V, Rogach A L, Hoppe K, Shevchenko E V, Kornowski A, Eychmuller A and Weller H 2002 Thiol-capping of CdTe nanocrystals: an alternative to organometallic synthetic routes J. Phys. Chem. B 106 7177-85

[8] Garon E B, Marcu L, Luong Q, Tcherniantchouk O, Crooks G M and Koeffler H P 2007 Quantum dot labeling and tracking of human leukemic, bone marrow and cord blood cells Leuk. Res. 31 643-51

[9] Jie G F, Wang L and Zhang S S 2011 Magnetic electrochemiluminescent $\mathrm{Fe}_{3} \mathrm{O}_{4} / \mathrm{CdSe}-\mathrm{CdS}$ nanoparticle/polyelectrolyte nanocomposite for highly efficient immunosensing of a cancer biomarker Chem.-Eur. J. 17 641-8

[10] Zajac A, Song D S, Qian W and Zhukov T 2007 Protein microarrays and quantum dot probes for early cancer detection Colloid Surf. B 58 309-14

[11] Baumle M, Stamou D, Segura J M, Hovius R and Vogel H 2004 Highly fluorescent streptavidin-coated CdSe nanoparticles: preparation in water, characterization, and micropatterning Langmuir 20 3828-31

[12] Donega C D, Liljeroth P and Vanmaekelbergh D 2005 Physicochemical evaluation of the hot-injection method, a synthesis route for monodisperse nanocrystals Small 1 1152-62

[13] Gao Y H, Liang C J, Tang A W, Teng F, Li D, Deng Z B and Huang S H 2007 Electroluminescence of cadmium selenium nanocrystals synthesized in aqueous solution J. Lumin. 122 646-8

[14] Rogach A L, Kornowski A, Gao M Y, Eychmuller A and Weller H 1999 Synthesis and characterization of a size series of extremely small thiol-stabilized CdSe nanocrystals J. Phys. Chem. B 103 3065-9

[15] Dameron C T and Winge D R 1990 Characterization of peptide-coated cadmium-sulfide crystallites Inorg. Chem. 29 1343-8

[16] Dameron C T and Winge D R 1990 Peptide-mediated formation of quantum semiconductors Trends Biotechnol. $83-6$

[17] Nayar S, Sinha A, Das S, Das S K and Rao P R 2001 In situ synthesis of nanosized cadmium sulfide using bovine serum albumin J. Mater. Sci. Lett. 20 2099-100

[18] Pearce C I, Coker V S, Charnock J M, Pattrick R A D, Mosselmans J F W, Law N, Beveridge T J and Lloyd J R 2008 Microbial manufacture of chalcogenide-based nanoparticles via the reduction of selenite using Veillonella atypica: an in situ EXAFS study Nanotechnology 19155603

[19] Wang Q S, Ye F Y, Fang T T, Niu W H, Liu P, Min X M and Li X 2011 Bovine serum albumin-directed synthesis of biocompatible CdSe quantum dots and bacteria labeling J. Colloid Interface Sci. 355 9-14

[20] Zheng Y G, Gao S J and Ying J Y 2007 Synthesis and cell-imaging applications of glutathione-capped CdTe quantum dots Adv. Mater. $19376-80$

[21] Zheng Y G, Yang Z C and Ying J Y 2007 Aqueous synthesis of glutathione-capped $\mathrm{ZnSe}$ and $\mathrm{Zn}_{1-x} \mathrm{Cd}_{x}$ Se alloyed quantum dots Adv. Mater. 19 1475-9

[22] Dameron C T, Reese R N, Mehra R K, Kortan A R, Carroll P J, Steigerwald M L, Brus L E and Winge D R 1989 Biosynthesis of cadmium-sulfide quantum semiconductor crystallites Nature 338 596-7 
[23] Kumar S A, Ansary A A, Ahmad A and Khan M I 2007 Extracellular biosynthesis of CdSe quantum dots by the fungus, fusarium oxysporum J. Biomed. Nanotechnol. 3 190-4

[24] Kowshik M, Deshmukh N, Vogel W, Urban J, Kulkarni S K and Paknikar K M 2002 Microbial synthesis of semiconductor CdS nanoparticles, their characterization, and their use in the fabrication of an ideal diode Biotechnol. Bioeng. 78 583-8

[25] Kowshik M, Vogel W, Urban J, Kulkarni S K and Paknikar K M 2002 Microbial synthesis of semiconductor $\mathrm{PbS}$ nanocrystallites Adv. Mater. 14 815-8

[26] Bao H F, Hao N, Yang Y X and Zhao D Y 2010 Biosynthesis of biocompatible cadmium telluride quantum dots using yeast cells Nano Res. 3 481-9

[27] Bai H J, Zhang Z M and Gong J 2006 Biological synthesis of semiconductor zinc sulfide nanoparticles by immobilized Rhodobacter sphaeroides Biotechnol. Lett. 28 1135-9

[28] Bao H F, Lu Z S, Cui X Q, Qiao Y, Guo J, Anderson J M and Li C M 2010 Extracellular microbial synthesis of biocompatible CdTe quantum dots Acta Biomater. 6 3534-41

[29] Smith P R, Holmes J D, Richardson D J, Russell D A and Sodeau J R 1998 Photophysical and photochemical characterisation of bacterial semiconductor cadmium sulfide particles J. Chem. Soc. Faraday Trans. 94 1235-41

[30] Sweeney R Y, Mao C B, Gao X X, Burt J L, Belcher A M, Georgiou G and Iverson B L 2004 Bacterial biosynthesis of cadmium sulfide nanocrystals Chem. Biol. 11 1553-9

[31] Wang Y L, Lu J P and Tong Z F 2010 Rapid synthesis of CdSe nanocrystals in aqueous solution at room temperature Bull. Mater. Sci. 33 543-6
[32] Pearce C, Pattrick R A D, Law N, Charnock J M, Coker V S, Fellowes J W, Oremland R S and Lloyd J R 2009 Investigating different mechanisms for biogenic selenite transformations: geobacter sulfurreducens, Shewanella oneidensis and Veillonella atypica Environ. Technol. 30 1313-26

[33] Lenz M and Lens P N L 2009 The essential toxin: the changing perception of selenium in environmental sciences Sci. Tot. Environ. 407 3620-33

[34] Klayman D L and Griffin T S 1973 Reaction of selenium with sodium-borohydride in protic solvents-facile method for introduction of selenium into organic-molecules $\mathrm{J}$. Am. Chem. Soc. 95 197-200

[35] Kvashnina K O, Butorin S M, Cui D, Vegelius J, Puranen A, Gens R and Glatzel P 2009 Electron transfer during selenium reduction by iron surfaces in aqueous solution: high resolution x-ray absorption study Proc. 14th Int. Conf. on X-Ray Absorption Fine Structure (Xafs 14) vol 190 p 012191

[36] Huder J B and Dimroth P 1993 Sequence of the sodium ion pump methylmalonyl-CoA decarboxylase from Veillonella parvula J. Biol. Chem. 268 24564-71

[37] Pattrick R A D, England K E R, Charnock J M and Mosselmans J F W 1999 Copper activation of sphalerite and its reaction with xanthate in relation to flotation: an x-ray absorption spectroscopy (reflection extended x-ray absorption fine structure) investigation Int. J. Miner. Process. 55 247-65

[38] Rogach A L 2000 Nanocrystalline CdTe and CdTe(S) particles: wet chemical preparation, size-dependent optical properties and perspectives of optoelectronic applications Mater. Sci. Eng. B 69 435-40 